\title{
STIFFNESS ANALYSIS OF 4-LINK COUPLER MECHANISM USED IN LOW FLOOR TRAMS
}

\author{
TOMASZ CZAUDERNA ${ }^{*}$ MICHAL MANIOWSKI ${ }^{* *}$ \\ Cracow City Transportation Company (MPK SA.), ul. Św. Wawrzyńca 13, 31-060 Cracow, Poland \\ ${ }^{*}$ Cracow University of Technology, Institute of Automobiles and IC Engines, adress \\ tczauder@mpk.krakow.pl, mmaniowski@pk.edu.pl
}

received 27 May 2015, revised 9 February 2017, accepted 13 February 2017

\begin{abstract}
The paper presents elastokinematic analysis of spatial, 4-link coupler system used in low floor tram power-trains with classic drive bogies. This article is a continuation of previous work, where were analysed only the kinematic properties of such coupling. In this paper, the experimental characterization of linear and angular stiffness of metal and rubber bushing installed in the coupler rods. Estimated stiffness coefficients were then inserted into the coupler model with compliant bushings jointed with perfectly rigid platforms and rods. Stiffness matrix of the coupler was calculated and its selected coefficients were interpreted.
\end{abstract}

Key words: Low Floor Tram, Power Train, Multi-Link Couplers, Elasto-Kinematic Analysis

\section{INTRODUCTION}

The paper goal is elasto-kinematic analysis of 4-link couplers (Flender) utilized in power trains (Fig.1a) of low-floor trams (Cracow City Transport Company, Madej, 2000).

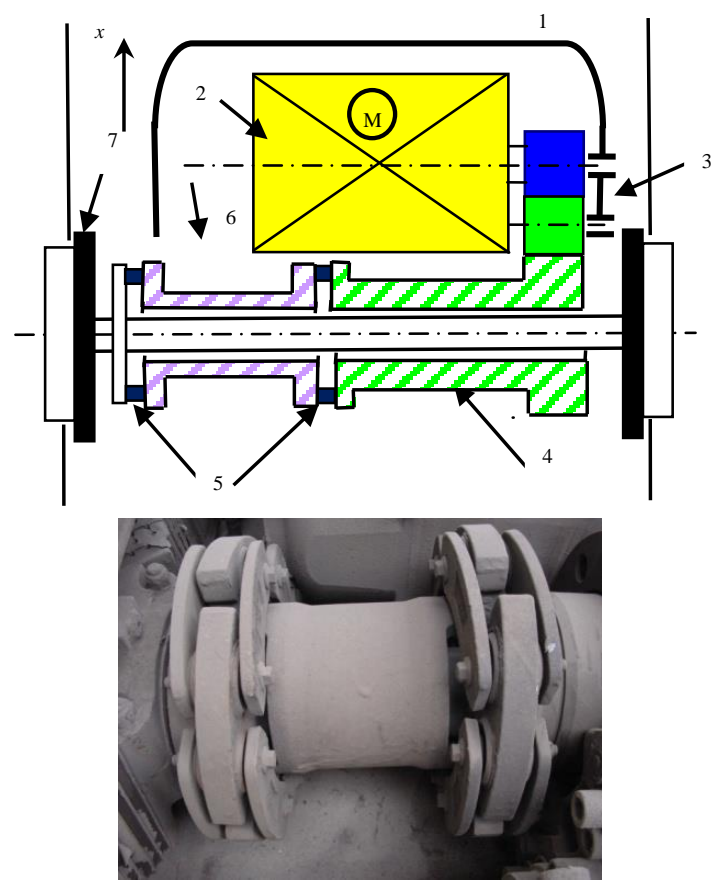

Fig. 1. Typical configuration of tram power train, b) actual 4-link coupler (FLENDER); (1) boogie, 2) electric motor, (3) reduction gear, (4) hollow, (5) four-link couplers, (6) intermediate hollow, (7) axle with rail wheels

These couplings are used to compensate for primary suspension misalignments in the bogie $(1-$ Fig.1a) with full torque
$(6000 \div 24000 \mathrm{Nm})$ transmission between the gear unit and the powered wheel set shaft. They permit very large shaft displacements and allow major misalignments between the axle and the gear unit while generating only very slight reaction forces.

In the actual 4-link coupler each link includes compliant bushings (Fig.1b), in form of steel-rubber sleeves, in order to obtain: vibroisolation level, increase of the coupler allowable displacements and the mechanism costs reduction (Czauderna and Maniowski, 2013).

Analyses of 4-link coupler spatial stiffness are not widely described. In most of known literature (Farshidianfar et al., 2000; Frączek et al., 2009; Madej, 2000; Zou et al., 2001) these types of couplers are considered as planar mechanisms. Algorithms for calculation of some components of such couplers stiffness are given in Madej (2000).

In this paper spatial stiffness matrices for: single cylindrical bushing, link with 2 bushings in series, and ultimately whole 4-link coupler, will be determined analytically based on tensor calculus (Farshidianfar et al., 2000).

\section{ELASTOKINEMATIC MODEL OF THE COUPLER}

\subsection{Model assumptions}

Kinematic scheme of the 4-link coupling mechanism is presented in Fig. 2. The mechanism model was formulated under the following assumptions (Czauderna and Maniowski, 2013; Madej, 2000):

- rods, shafts and platforms are assumed to be rigid;

- the only source of the system compliance comes frommetalrubber bushings (Fig.3) which act as joints in points $A_{i}$ and $B_{i}$ of the clutch;

- elastokinematic analysis is performed for small, quasi-static displacements;

- the bushings exhibit linear force-deflection characteristics; 
- the bushings are described by coaxial symmetry;

- the active shaft (with the reference system $X_{a} Y_{a} Z_{a}$ ) rotates only around its own axis coinciding with $O Y$ axis;

- the passive shaft is described by reference system $X_{b} Y_{b} Z_{b}$.

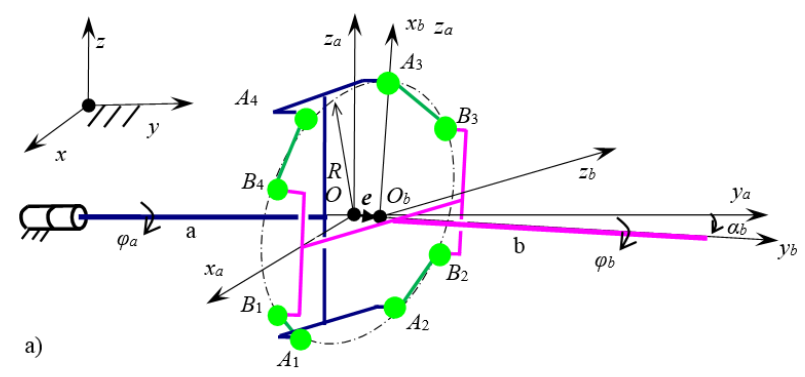

b)

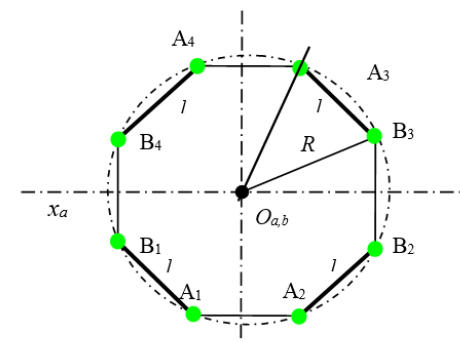

Fig. 2. Scheme of the 4 -link coupler mechanism in general pose (a), Dimensions of the coupler in $x-z$ plane (b)

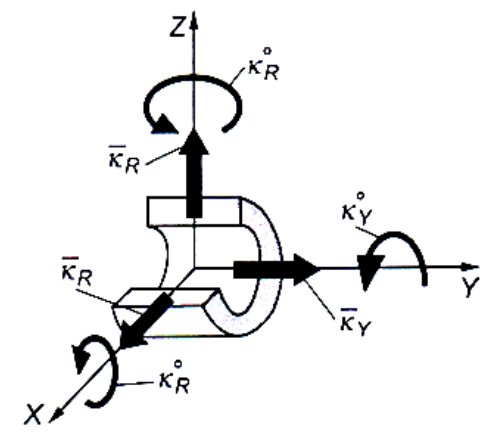

Fig. 3a. Scheme of cylindrical bushing with elastomeric insert (Madej, 2000)

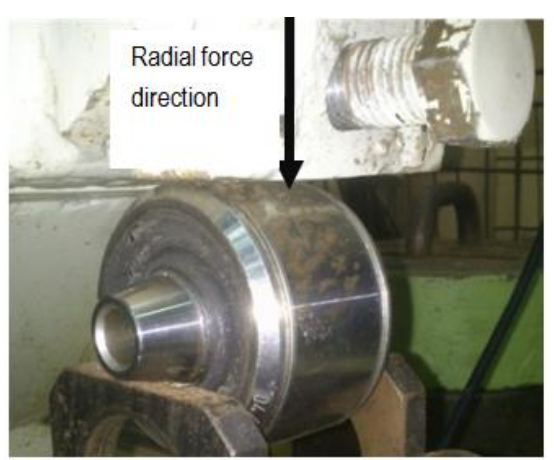

Fig. 3b. Actual bushing installed in test rig

\subsection{Compliant bushing model}

With the above assumptions, problem of the bushing stiffness (Fig.3a) is described as follows:
$\mathbf{w}_{B}=\mathbf{K}_{B} \Delta \mathbf{p}_{B}$

where:

$\Delta \boldsymbol{p}_{\boldsymbol{B}}=\left[\begin{array}{c}\Delta x \\ \Delta y \\ \Delta z \\ \Delta \alpha \\ \Delta \varphi \\ \Delta \theta\end{array}\right]$

- spatial displacement vector of the sleeve, where the linear displacement is expressed in [m], and angular displacement in [rad];

$\mathbf{w}_{B}=\left[\begin{array}{l}f_{x} \\ f_{y} \\ f_{z} \\ m_{x} \\ m_{y} \\ m_{z}\end{array}\right]$

- spatial load vector on the bushing, where force components are expressed in [N], and the components of torque in [Nm];

$\mathbf{K}_{B}=\left[\begin{array}{llllll}k_{11} & & \cdots & & & 0 \\ & k_{22} & & & & \\ & & k_{33} & & & \\ \cdots & & & k_{44} & & \\ & & & & k_{55} & \\ 0 & & & & & k_{66}\end{array}\right]$

- symmetric stiffness matrix of the sleeve with the stiffness coefficients on the matrix diagonal only.

Tab. 1. Coefficients of the bushing stiffness determined from measurements

\begin{tabular}{|l|l|l|}
\hline $\begin{array}{l}\text { Stiffness } \\
\text { coefficients } \\
\text { accord. to eq. (4) }\end{array}$ & $\begin{array}{l}\text { Notations } \\
\text { from [9] }\end{array}$ & $\begin{array}{l}\text { Measurements } \\
\text { results }\end{array}$ \\
\hline $\mathrm{k}_{11}=\mathrm{k}_{33}$ & $\mathrm{~K}_{\mathrm{R}},[\mathrm{N} / \mathrm{m}]$ & $3.92 \times 10^{6} \pm 5 \%$ \\
\hline $\mathrm{k}_{22}$ & $\mathrm{k}_{\mathrm{y}}[\mathrm{N} / \mathrm{m}]$ & $1.66 \times 10^{6} \pm 5 \%$ \\
\hline $\mathrm{k}_{44}=\mathrm{k}_{66}$ & $\mathrm{~K}_{\mathrm{Ro}}[\mathrm{Nm} / \mathrm{rad}]$ & $1410 \pm 5 \%$ \\
\hline $\mathrm{k}_{55}$ & $\mathrm{~K}_{\mathrm{yo}}[\mathrm{Nm} / \mathrm{rad}]$ & $797 \pm 5 \%$ \\
\hline
\end{tabular}

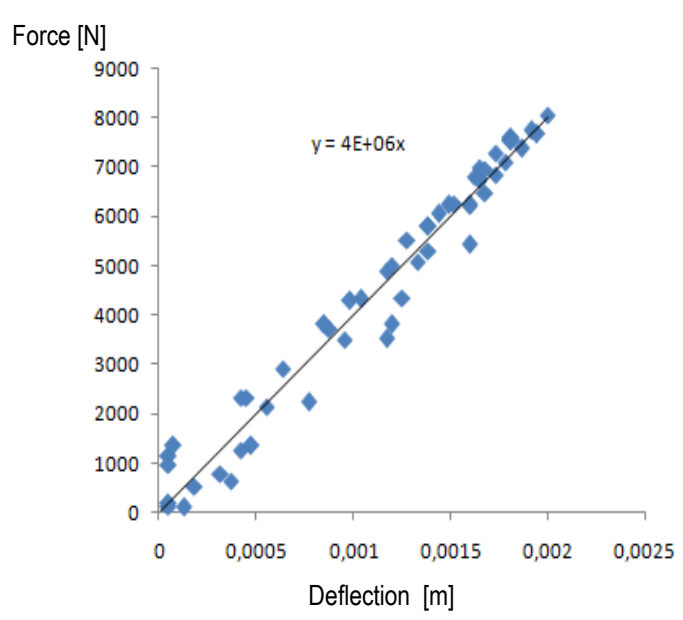

Fig. 4. Radial stiffness characteristic of the considered bushing from measurements 
Bushing stiffness parameters in Eq. 4 were determined on the basis of measurements on the test rig (Fig. $3 b$ ). Sample of radial force-deflection characteristics is presented in Fig. 4. The considered bushing with rubber insert exhibits linearity in all directions. Determined coefficients of the bushing stiffness are given in Tab. 1.

\subsection{Model of coupler link with 2 bushings}

Coupler link (Fig. 5), with length $\mathrm{l}$, can be treated as a serial connection of two compliant bushings, located in points $A_{i}$ and $B_{i}$ along longitudinal axis $(\mathrm{x})$. It is assumed that the bushings have the same stiffness $\left(\mathrm{K}_{\mathrm{B}}\right)$ and orientation. Substitute stiffness matrix $\left(K_{L}\right)$ of the coupler link, reduced to joint $A_{i}$, is to be evaluated according to the following formula:

$$
\mathbf{K}_{L}=\left[\mathbf{J}_{L}\left(\mathbf{K}_{B}{ }^{-1}\right) \mathbf{J}_{L}{ }^{T}+\mathbf{K}_{B}{ }^{-1}\right]^{-1}
$$

where:

$\mathbf{J}_{L}=\left[\begin{array}{ll}{[\mathbf{1}]_{3 \times 3}} & {[\tilde{\mathbf{1}}]_{3 \times 3}} \\ {[\mathbf{0}]_{3 \times 3}} & {[\mathbf{1}]_{3 \times 3}}\end{array}\right]$

- means a jacobian matrix of transformation of point $B$ to $A$ on the link.

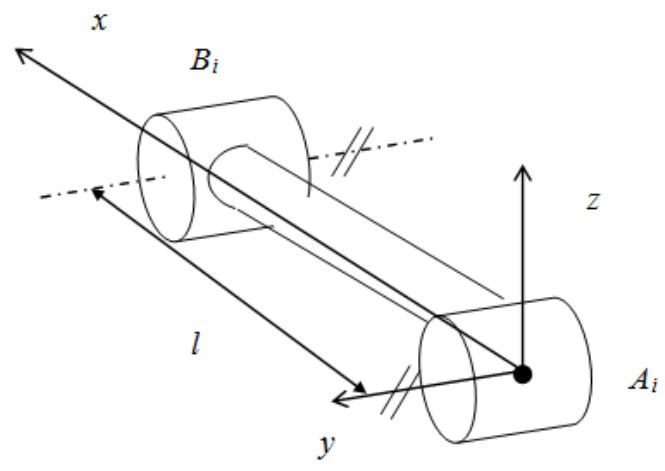

Fig.5. Model of the coupler link with two bushings
Equation (5) concerns a serial connection of two elastic elements, through summing its flexibilities (inverse of the stiffness). Inversion of the diagonal stiffness matrix (4) is straightforward.

In case when the link orientation has to be changed, its stiffness matrix (5) can be transformed in the following way:

$\mathbf{K}_{L R}=\mathbf{H}^{T} \mathbf{K}_{L} \mathbf{H}$

where:

$\mathbf{H}=\left[\begin{array}{ll}{[\mathbf{R}]_{3 \times 3}} & {[\mathbf{0}]_{3 \times 3}} \\ {[\mathbf{0}]_{3 \times 3}} & {[\mathbf{R}]_{3 \times 3}}\end{array}\right]$

$\boldsymbol{R}$ - orthogonal orientation matrix of the link.

\subsection{Model of the coupler with 4 links}

The whole coupler mechanism (Fig. 2) can be treated as parallel connection of 4 links described by stiffness matrix (7). Therefore, the coupler stiffness matrix represents a summation of the link stiffnesses transformed to the center of the platform:

$\mathbf{K}_{C}=\sum_{i=1}^{4} \mathbf{J}_{C, i} \mathbf{K}_{L R, i} \mathbf{J}_{C, i}{ }^{T}$

where:

$\mathbf{J}_{C}=\left[\begin{array}{ll}{[\mathbf{1}]_{3 \times 3}} & {[\tilde{\mathbf{a}}]_{3 \times 3}} \\ {[\mathbf{0}]_{3 \times 3}} & {[\mathbf{1}]_{3 \times 3}}\end{array}\right]$

ã - skew symmetric matrix from vector a, describing position of $B$ point with respect to A point on the coupler link.

\section{NUMERICAL EXAMPLE}

Numerical example concerns the 4-link coupler according to Fig. 2 with dimensions:

$$
\begin{aligned}
& l_{o}=0.1305 \mathrm{~m} ; \\
& \gamma=0.2967 \mathrm{rad} .
\end{aligned}
$$

The bushing (Fig. 3) stiffness matrix $K_{B}$ (4), supplemented by the stiffness coefficients determined from measurements, is as follows:

$\mathrm{K}_{\mathrm{B}}=10^{6}\left(\begin{array}{llllll}3.92 & 0 & 0 & 0 & 0 & 0 \\ 0 & 1.66 & 0 & 0 & 0 & 0 \\ 0 & 0 & 3.92 & 0 & 0 & 0 \\ 0 & 0 & 0 & 1.41 & 0 & 0 \\ 0 & 0 & 0 & 0 & 0.797 & 0 \\ 0 & 0 & 0 & 0 & 0 & 1.41\end{array}\right)$

The bushing exhibits the highest linear stiffness $(3.92 \mathrm{e} 6 \mathrm{~N} / \mathrm{m})$ in both radial ( $\mathrm{x}$ and $\mathrm{z}$ ) directions. Axial (y) linear stiffness is about two times lower.

The coupler link (Fig. 5) jacobian matrix (6) is given below:

$$
J_{L}=\left(\begin{array}{llllll}
1 & 0 & 0 & 0 & 0 & 0 \\
0 & 1 & 0 & 0 & 0 & -0.1305 \\
0 & 0 & 1 & 0 & 0.1305 & 0 \\
0 & 0 & 0 & 1 & 0 & 0 \\
0 & 0 & 0 & 0 & 1 & 0 \\
0 & 0 & 0 & 0 & 0 & 1
\end{array}\right)
$$

The stiffness matrix (5) of the horizontal link (Fig.5) is as follows: 
$\mathrm{K}_{L}=10^{6}\left(\begin{array}{llllll}1.96 & 0 & 0 & 0 & 0 & 0 \\ 0 & 0.0893 & 0 & 0 & 0 & 0.0058 \\ 0 & 0 & 0.138 & 0 & -0.009 & 0 \\ 0 & 0 & 0 & 0.0007 & 0 & 0 \\ 0 & 0 & -0.009 & 0 & 0.0013 & 0 \\ 0 & 0.0058 & 0 & 0 & 0 & 0.0008\end{array}\right)$

The link exhibits the highest linear stiffness $(1.96 \mathrm{e} 6 \mathrm{~N} / \mathrm{m})$ in $x$ direction, that is longitudinal link axis. Other $(\mathrm{y}$ and $\mathrm{z})$ linear stiffnesses are about 10 times lower. Besides the main stiffness coefficients on the diagonal (13), there appear cross-stiffness coefficients also.

Ultimately, numerical representation of the 4-link coupler (Fig.2) stiffness matrix (9) is as follows:

$\mathrm{K}_{C}=10^{6}\left(\begin{array}{llllll}4.0986 & 0 & 0 & 0 & 0 & 0 \\ 0 & 0.5521 & 0 & 0 & 0 & 0 \\ 0 & 0 & 4.0986 & 0 & 0 & 0 \\ 0 & 0 & 0 & 0.0079 & -0.0007 & 0.0032 \\ 0 & 0 & 0 & -0.0007 & 0.0444 & 0.0034 \\ 0 & 0 & 0 & 0.00032 & 0.0034 & 0.0035\end{array}\right)$

The 4-link coupler exhibits the lowest linear stiffness $(0.5521 \mathrm{e} 6 \mathrm{~N} / \mathrm{m})$ in y direction, what is utilized to take over relative displacements of the coupler axles. Linear stiffness of the coupler in radial directions ( $\mathrm{x}$ and $\mathrm{z}$ ) is ten times greater due to links action. The highest torsional stiffness $(0.0444 \mathrm{e} 6 \mathrm{Nm} / \mathrm{rad})$ the coupler exhibits about y axis, what is needed for effective transmission of (Fig. 1) engine torque. Two other axes ( $\mathrm{x}$ and $\mathrm{z}$ ) are described by low angular stiffness, what enables compensation of the coupler axles slope.

\section{CONCLUSIONS}

Formulated elastokinematic model enables to analysis of the 4-link coupler design parameters on spatial stiffness of the considered mechanism. Stiffness characteristics of the metal-rubber joints were determined on the basis of test rig measurement.

The single 4-link coupler exhibits the greatest linear stiffness in radial directions ( $\mathrm{x}$ and $\mathrm{z}$ ). Stiffness in longitudinal direction (y axis) is about 8 times less, enabling slight compensation of axial displacements of the coupler axles. The coupler exhibits the greatest torsional stiffness about $y$ axis, where the powertrain torque can be transferred. In other directions the coupler torsional stiffness is 7 times less, making possible slight variations of the axles inclination.

Further works include measurements of the actual 4-link coupler used in NGT6 low floor trams in Cracow city transport. Formulation of the 4-link coupler dynamic model is also planned.

\section{REFERENCES}

1. Cracow City Transport Company (MPK SA.)

2. Czauderna T. (2012), Kinematic analysis of spatial double 4-link coupler system used in low floor tram (in Polish), Conference of Modern Rail Technologies, 103-118.

3. Czauderna T., Maniowski M. (2013), Elastic-kinematic analysis of spatial 4-link coupler system (in Polish), Conference of Modern Rail Technologies, 61-72.

4. Czauderna T., Grzyb A. (9/2009), Reaserch on kinematic excitations of trams vibrations (in Polish), Rail Transport Engineering, 64-68.

5. Farshidianfar, M. Ebrahimi, H. Rahnejat, Menday M.T (2000), Low-frequency torsional vibration of vehicular driveline systems in shuffle, Multibody Dynamics: Monitoring \& Simulation Techniques, Editors: Homer Rahnejat, Morteza Ebrahimi, Robert Whalley; 263-282.

6. Frączek J., Wojtyra M. (2009), Kinematics of multibody systems (in Polish), Technical Edition, Warsaw.

7. Knapczyk J., Maniowski M. (2006), Elastokinematic Modeling and Study of Five-Rod Suspension with Subframe, Mechanism and Machine Theory, 41, 1031-1047.

8. Madej J. (2000), Mechanics of drive torque transmission (in Polish, Publishing House of Warsaw University of Technology.

9. Quennouelle C., Gosselin C. M. (2008), Stiffness Matrix of Compliant Parallel Mechanisms, Advances in Robot Kinematics: Analysis and Design, Editors: Jadran Lenarcic, Philippe Wenger, 331-341.

10. Romaniszyn Z. (2005), Boogies suspensions of rail vehilces (in Polish), Publishing House of Cracow University of Technology.

11. Zou Z., Zhang Y., Zhang X., Tobler W. (2001), Modelling and Simulation of Traction Drive Dynamics and Control, Journal of Mechanical Design, 123(4), 556-561. 